\title{
DRIFTING TOGETHER OR FALLING APART? THE EMPIRICS OF REGIONAL ECONOMIC GROWTH IN POST-UNIFICATION GERMANY
}

\author{
ROBERTA COLAVECCHIO \\ DECLAN CURRAN \\ MICHAEL FUNKE
}

CESIFO WORKING PAPER NO. 1533

CATEgOry 5: Fiscal Policy, Macroeconomics AND GROWTH SEPTEMBER 2005

An electronic version of the paper may be downloaded

- from the SSRN website:

www.SSRN.com

- from the CESifo website:

www.CESifo-group.de 


\title{
DRIFTING TOGETHER OR FALLING APART? THE EMPIRICS OF REGIONAL ECONOMIC GROWTH In POST-UNIFICATION GERMANY
}

\begin{abstract}
The objective of this paper is to address the question of convergence across German districts in the first decade after German unification by drawing out and emphasising some stylised facts of regional per capita income dynamics. We achieve this by employing non-parametric techniques which focus on the evolution of the entire cross-sectional income distribution. In particular, we follow a distributional approach to convergence based on kernel density estimation and implement a number of tests to establish the statistical significance of our findings. This paper finds that the relative income distribution appears to be stratifying into a trimodal/bimodal distribution.
\end{abstract}

JEL Code: C14, R11, R12.

Keywords: regional economic growth, Germany, convergence clubs, density estimation, modality tests.

\author{
Roberta Colavecchio \\ Department of Economics \\ Hamburg University \\ Von-Melle-Park 5 \\ 20146 Hamburg \\ Germany \\ colavecchio@econ.uni-hamburg.de
}

\author{
Declan Curran \\ Department of Economics \\ Hamburg University \\ Von-Melle-Park 5 \\ 20146 Hamburg \\ Germany \\ curran@econ.uni-hamburg.de
}

\author{
Michael Funke \\ Department of Economics \\ Hamburg University \\ Von-Melle-Park 5 \\ 20146 Hamburg \\ Germany \\ funke@econ.uni-hamburg.de
}

We would like to thank Stephanie Jasmand for her excellent research assistance. The usual disclaimer applies. 


\section{Introduction}

When, on October $3^{\text {rd }} 1990$, the 60 million Germans in the West were formally re-united with the 16 million Germans in the East, the two parts could hardly have been more different. Despite a common culture and language, after forty years of development with radically different economic institutions and incentives, the Federal Republic of Germany and the German Democratic Republic (GDR) were characterized by substantial disparities in physical and human capital, labour productivity, incomes and wealth. According to Sinn and Sinn (1992), GDP per person in East Germany in 1989 was only 60 percent of the West German level. The West was one of the technologically most advanced and richest countries in the world; the East was economically shattered after four decades of communism and nearly bankrupt. In the years leading up to unification, real GDP growth was steady in the former West Germany and the unemployment rate was stable. After unification, the Western states experienced sharper business cycle fluctuations: a modest upturn in 1990-91 was followed by a sharp recession in 1992-93, both of which were mainly due to the unification process. The initial economic boom was led by "exports" to the Eastern states, where consumers were switching to cheaper and better quality goods produced in the West. Moreover, the German government financed its initial transfers to the GDR by borrowing, a choice which stimulated an economy already near its output potential and triggered a widening fiscal deficit. The subsequent recession was also closely related to unification. Restrictive measures were implemented to reduce the fiscal deficit and the Bundesbank tightened monetary policy to cap the rising inflation. These policy responses, coupled with a contraction in foreign demand, had a dampening effect on the economy and the postunification boom gradually turned into a deep recession, with GDP growth rates well below the historical average for Western Germany. Indeed, the major cost of unification for Western regions in the years immediately following unification was a lower income growth rate and thus the issue of convergence of GDP growth rates among German regions in the last decade is still an open question. In particular, the problem of uneven regional developments has been closely monitored in economic policy debates and in recent years there has been a surge in empirical work on growth and convergence.

When considering regional convergence, various empirical approaches have been implemented in the literature: from simple plots of measures of dispersion over time to intra-distributional dynamics using Markov chains applied to GDP per capita. Numerous studies have revealed persistent differences in per capita income among regions. Evidence shows that some regions managed to sustain high per capita income over a long time span while other regions seemed to be trapped in a low income growth path. These persistent differences are strikingly at odds with the standard neoclassical growth model, which predicts that poorer countries usually develop faster than richer ones and that there is a tendency toward convergence in levels of GDP per capita. A key feature of the neoclassical growth model has been the assumption of identical production functions for all 
regions. As a consequence, a single dynamic model is adequate to characterise all cross-region growth behaviour. ${ }^{1}$ On the other hand there exists an opposing growth paradigm [see, for example, Azariadis and Drazen (1990)] explaining multiple steady states in the growth rate of per capita income. According to Azariadis and Drazen (1990) and Aghion and Howitt (1998, chapter 10), multiple locally stable equilibria can be attributed to differences in initial conditions. Faini (1984) has initially considered multiple steady states in the context of regional development issues. ${ }^{2}$ In all these models, different initial conditions may cause regions to get stuck at different self-perpetuating levels of economic activity. As suggested by Quah $(1996,1997)$ and Paap and van Dijk (1998), this may lead to a polarisation into clubs of rich and poor countries or regions. ${ }^{3}$

Research on convergence has accommodated cross-regional heterogeneity in a sequence of stages. At first, conventional cross-section analysis [see, for example, Barro (1991) and Mankiw et al. (1992)] assumed complete homogeneity in steady state growth rates. Recently, Lee et al. (1997, 1998) allowed complete heterogeneity in steady state growth rates. However, as pointed out by Islam (1998), extensions that allow varying growth rates run the risk of robbing the concept of convergence of any economic meaning. Instead of assuming complete heterogeneity, we set a structure of an intermediate form: we advocate techniques which focus on the evolution of the entire cross-sectional distribution in addressing the question of convergence across German districts in the first decade after German unification. ${ }^{4}$ In this context, a convergence process occurs if, for instance, a bimodal density is detected at the beginning of the sample period and over time there is a tendency in the distribution to move towards unimodality. Alternatively, if there already is a unimodal distribution after German unification, convergence occurs when the dispersion of this density and therefore per capita income declines over time. ${ }^{5}$ To the best of our knowledge, no papers have attempted to formally test the convergence club hypothesis across East and West German regions

\footnotetext{
${ }^{1}$ It should be noted that the concept of $\beta$-convergence has a twofold connotation, absolute and conditional convergence. The former implies that the process of convergence can be observed regardless of other characteristics of the region. In contrast, the latter implies that convergence is observed only when holding constant a number of conditioning variables.

${ }^{2}$ Nelson (1956) is the grandfather of low-level equilibrium trap models.

${ }^{3}$ The obvious difficulty here is to figure out in the data which countries are in the bad and which ones are in the good equilibrium. Barrier to getting out of such a trap can be the lack of a "big push" [see Murphy et al. (1989)]. Rodrik (1996) has argued that the East Asian miracle may have depended on a state-assisted process of overcoming coordination failure, and a consequent shift between two different equilibrium output levels (or a virtuous circle). It is also worth noting that the possibility of non-uniqueness is discussed informally even in Solow's (1956) original exposition of the neoclassical growth model.

${ }^{4}$ In this paper we add to the contributions of Bianchi (1997), Corrado et al. (2005), Lopez-Bazo et al. (1999) and Pittau (2005) testing for "two-club" or "twin-peak" convergence of GDP per capita across countries and EU regions by analysing data which do not overlap with the data of existing papers. Magrini (2004), p. 2744) maintains that "[...] the distributional approach to convergence - particularly when based on nonparametric kernel estimations - appears to be generally more informative than convergence empirics within the regression approach, and therefore represents a more promising way forward".

${ }^{5}$ Economic and social cohesion is embedded in the German constitution (,Verfassung"). Regional income inequalities are therefore a major concern for policy-makers and substantial fiscal transfers are offered to less developed regions which aim at reducing undesired income disparities across regions.
} 
after unification. ${ }^{6}$ It is our purpose to detect whether clubs exist and which regions are associated with which clubs. A natural approach to assess the evolution over time of the dispersion of the regional per capita income is to estimate the cross-section distributions by using kernel density estimation.

The remainder of the paper is structured as follows. Section 2 describes the data set used for this study together with the non-parametric estimates of the per capita regional GDP over time. To support the visual impression given by kernel density estimates, and to provide further insight on the features of the underlying density, we have performed several statistical tests, whose results are presented in section 3 and 4. In particular, section 3 reports the outcome of a non-parametric test for multimodality, along with a set of maps which provide an illustration of the spatial structure of the real GDP per capita across German districts. Section 4 presents the results of a parametric test of density time invariance. Conclusions, implications for policy, and suggestions for future research appear in the last section.

\section{Data issues and empirical evidence from non-parametric density estimation}

The opportunity to assess spatial disparity trends in per capita income indicators is limited by the availability of consistent and comparable data. Long and dense time series for small geographic units are difficult to obtain, and in many cases not existent. In this section, we briefly present the spatial distribution of our data which are at the heart of our analysis. There are three levels of administration in Germany: (1) the Federal Republic at the national level; (2) 16 federal states (Bundesländer) on the regional level and (3) 439 districts (Kreise) or towns with autonomous administration (kreisfreie Städte), both on the local level. Smaller municipalities belong to the districts. In our empirical work below we focus on these 439 districts covering the entire economy. ${ }^{7}$ Our data run from 1992 to $2001 ; 2001$ is the latest year available to us and data prior to German unification are not available. Data for 1993 are missing. The source of our data is the "Arbeitskreis Volkswirtschaftliche Gesamtrechnung der Länder". ${ }^{8}$ The GDP per capita data are at constant 1995 prices and are obtained dividing the GDP of the German districts by their population. Ideally, we

\footnotetext{
${ }^{6}$ For example, Bode (2002) has continued to employ a single model for all regions even though the existence of convergence clubs is supported by empirical evidence and certain theoretical reasoning. Funke and Niebuhr (2005) have demonstrated the existence of two clubs across West German regions prior to unification using threshold estimation techniques.

${ }^{7}$ We focus on district-level data because state-level data tend to ,aggregate away" important differences between smaller geographic entities within the 16 states. For example, in the dataset that we analyse below, the ratio of GDP per capita between the richest (Hamburg) and the poorest state (Sachsen-Anhalt) was 2.63 in 2001, while the corresponding ratio for the richest (Landkreis München) and the poorest district (Mittlerer Erzgebirgskreis) was 7.30. On the other hand, one has to be aware that district-level GDP per capita figures may be affected by a commuting bias. Especially, commuters could overstate GDP per capita in agglomerations and city regions. Hamburg and Berlin are classified as a single region. This was forced on us because of lack of district-level data for both states. We also run the Kernel estimates excluding Berlin and Hamburg. Qualitatively, results are unchanged and the pattern is not much affected.
} 
should deflate district-level per capita incomes using district-level deflators but, since district-level price indices are not available, we follow the usual practice and simply use the 16 state-level GDP deflators.

Nonparametric density estimations can reveal several features of the data and therefore help to capture the stylised facts that need explanation, exploring which specifications match with the data. This is in the spirit of the specification searches of Sims and Uhlig's (1991) "helicopter tour". The kernel estimator for the density function $f(x)$ at point $x$ is

$$
\hat{f}(x)=\frac{1}{n h} \sum_{i=1}^{n} K\left(\frac{x_{i}-x}{h}\right)
$$

where $x=x_{1}, x_{2}, \ldots, x_{n}$, is an independent and identically distributed sample of random variables from a probability density $f(x)$ and $K(\cdot)$ is the standard normal kernel with window width $h$. The window width essentially controls the degree to which the data are smoothed to produce the kernel estimate. The larger the value of $h$, the smoother the kernel distribution. A crucial issue is the selection of this smoothing parameter. In order to solve the trade-off between oversmoothing and undersmoothing, i.e. the trade-off between bias and variance, we have first used Silverman's (1986) "first generation" rule-of-thumb for a Gaussian kernel. ${ }^{9}$ Additionally, we consider the two-stage direct plug-in bandwidth selection method of Sheather and Jones (1991), which has been shown to perform quite well for many density types by Park and Turlach (1992) and Wand and Jones (1995). ${ }^{10}$ The distributions have been fitted to the logarithm of real per capita income. In Figures 1 and 2 are plotted the kernel density estimations for the (log) GDP from 1992 to 2001 obtained using the two abovementioned bandwidth selection methods and by transforming the income variable to the original scale. ${ }^{11}$ The figures show similar patterns, validating the fact that the estimates are robust with respect to the bandwidth specification. Nevertheless, as expected, the Silverman (1986) rule of thumb returns a slightly larger optimal smoothing parameter and therefore the relative density estimate (Figure 1) appears oversmoothed compared to the one obtained used the Sheather and Jones (1991) plug-in method (Figure 2).

\footnotetext{
${ }^{8}$ See http://www.statistik-bw.de/Arbeitskreis_VGR/publikationen.asp.

${ }^{9}$ The properties of this rule may be seen in Silverman (1986), pp. 45-48. In the estimates below we have used the modified "Silverman's rule of thumb", as in (3.31), p. 48 of Silverman (1986).

${ }^{10}$ Our primary objective was to choose a bandwidth selection procedure that performs well for heavy tailed densities. Another concern is that some selectors have excellent asymptotic properties but very poor performance with small samples. This is why it is important to look more deeply in comparing alternative bandwidth selectors.

${ }^{11}$ Before plunging into the calculations, it is worthwhile to stress the limits of the purely statistical devices. They are useful in identifying interesting patterns and regularities but, by their very nature, do not uncover the ultimate reasons why some districts are much richer than others, even at a modest growth accounting level. Instead, it should be understood as a diagnostic tool - just as medical tests can tell one whether or not he is suffering from a certain ailment but cannot reveal the causes of it. This does not make the test any the less useful.
} 
Figure 1: Non-parametric densities of per capita GDP (constant 1995 prices) across German districts using Silverman's (1986) “first generation" rule-of-thumb
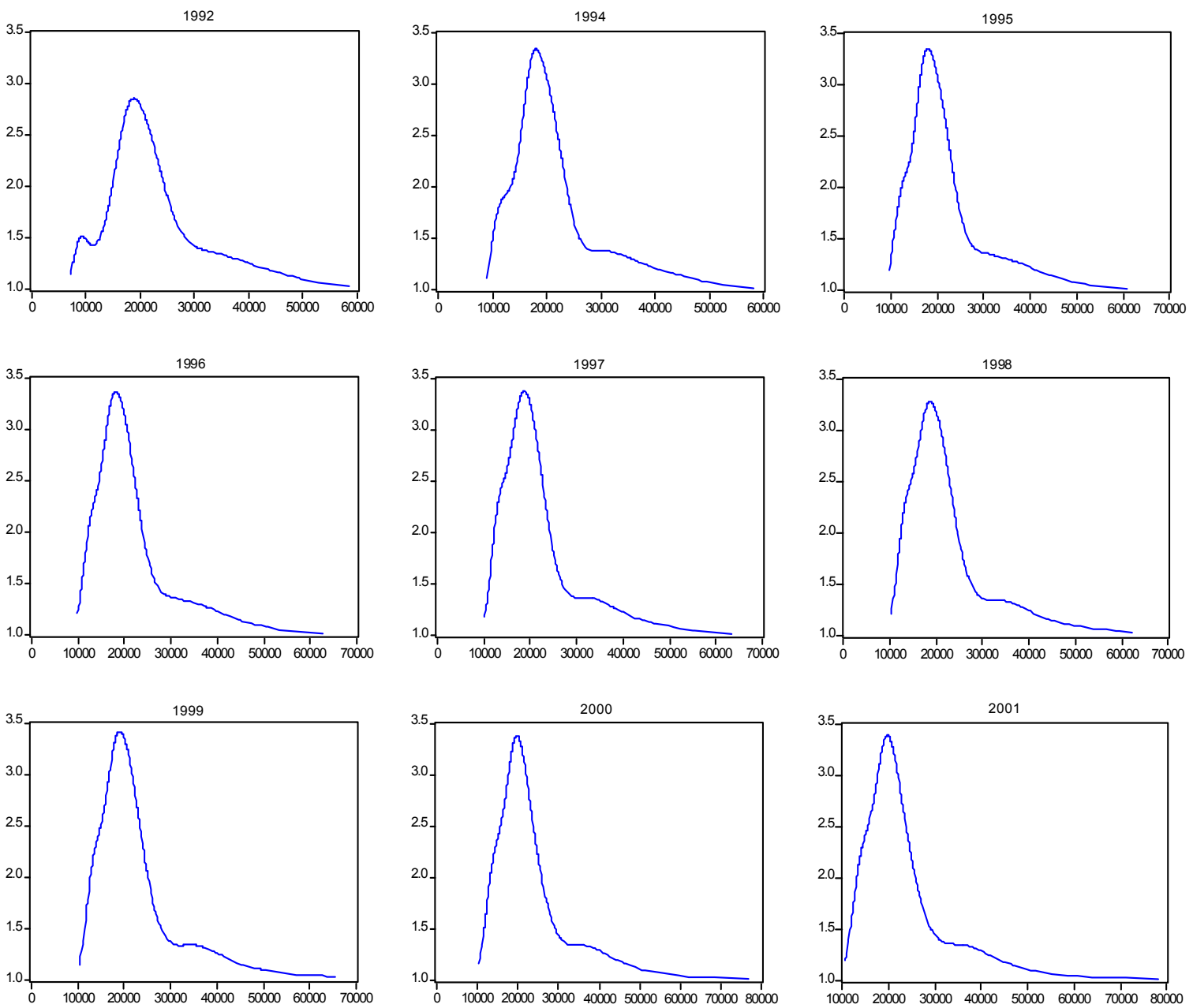
Figure 2: Non-parametric densities of per capita GDP (constant 1995 prices) across German districts using the plug-in bandwidth selection method of Sheather and Jones (1991)
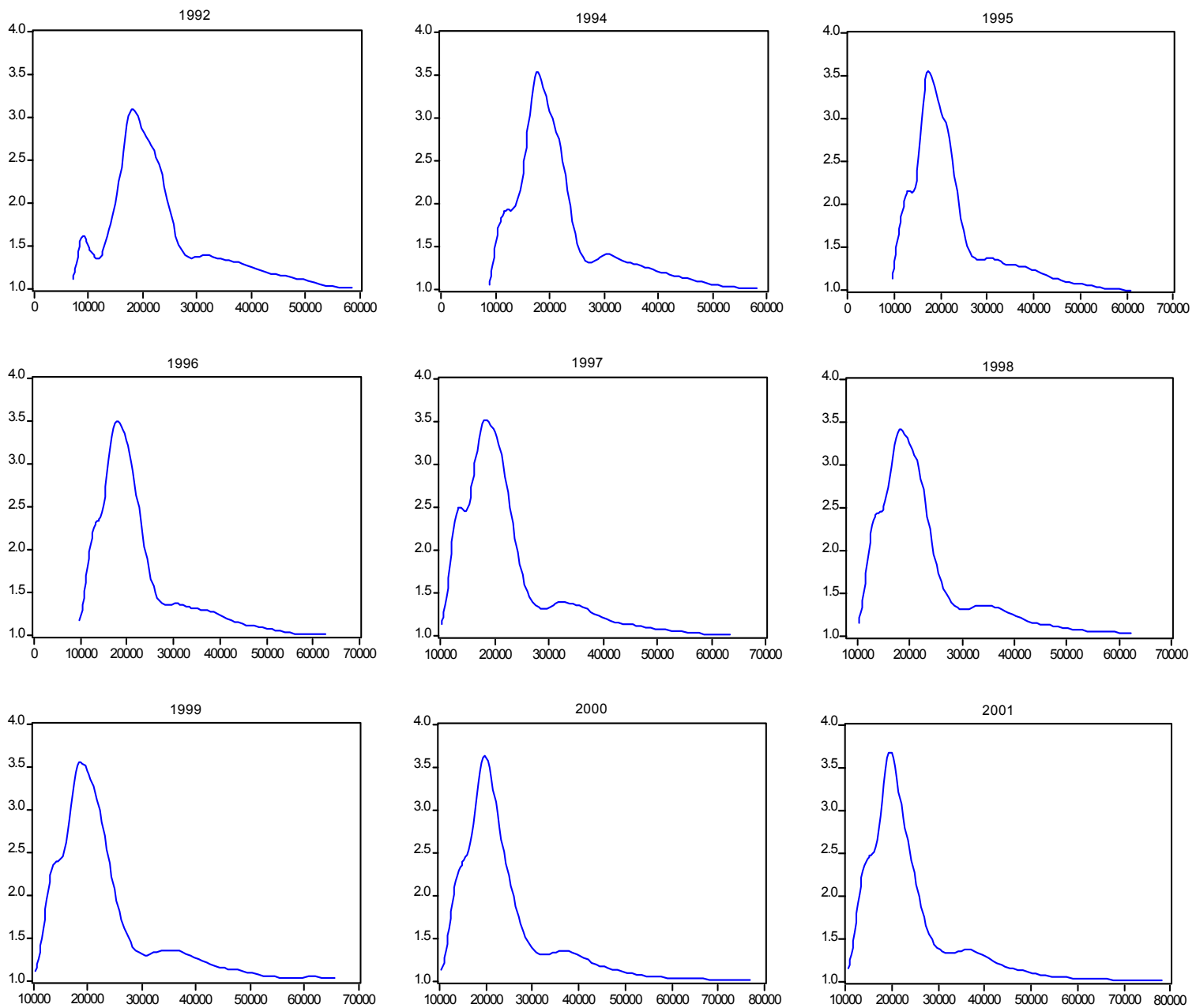

A preliminary inspection of the estimated densities reveals several noteworthy aspects. First, the snapshots show pronounced triple peakedness at the beginning of the considered time span. This evidence indicates that the German districts in 1992 can be separated into three groups, poor, rich and middle income. Second, as time passes this triple peakedness becomes less visible as the mode corresponding to low-income level recedes somewhat, without disappearing entirely as Figure 1 would have us believe. ${ }^{12}$ As we will see, this bimodal/trimodal ambiguity recurs later when we utilize statistical tests for multimodality. Either way, this smoothing of the third mode is indicative of an improvement in economic conditions of the German poorest districts. In particular, this smoothing of the initial trimodality supports the notion of a catching-up process of eastern Germany at the beginning of the 1990 s, i.e. the poorest districts did not stay as poor as they were immediately after unification. That said, despite the tendency of initially poor units to increase relative incomes,

${ }^{12}$ A "mode" is meant here to be a point on the empirical density estimate around which the tangent to the curve changes its slope from positive to negative. 
on average, over the considered decade, several districts experienced negative growth rates. ${ }^{13}$ Third, there is a visible tendency for the remaining two peaks to move apart, with the third mode moving to the right towards a higher income level. Moreover, the variability of the "low-mean distribution" has been declining over the decade from 1992 to 2001 and in 2001 appears to be considerably smaller than the spread of the "high-mean distribution". This evidence reveals that cross regional income disparity has become larger rather than smaller as predicted by absolute convergence.

However, the discussion above has relied heavily on the visual impression and shape of the nonparametric income densities. In practical terms, looking at Figure 1 and 2, the question to ask is: are those districts randomly drawn from an unimodal distribution, a bimodal distribution or is there any kind of trimodality? In order to shed further light on the structure of the underlying density function and in particular about the number of unobserved modes, in the following two sections we performed several statistical tests connected to kernel density estimates.

\section{Tests for multimodality}

The aim of this section is to give a short overview of the statistical method applied in this paper to test for convergence clubs.

In order to assess the issue of multimodality, we first calculate the Timm (2002) bimodality index (BM) for the real GDP per capita for each year of the considered time sample. The BM index is defined by:

$$
B M=\frac{m_{3}^{2}+1}{\frac{m_{4}+3(n-1)^{2}}{(n-2)(n-3)}},
$$

where $m_{3}$ is the skewness coefficient, $m_{4}$ is the kurtosis coefficient, and $n$ is the number of observations. Values bigger than 0.55 indicate the existence of bimodal or multimodal distributions. The results are reported in in Table 1. The values of the index are all above the critical threshold of 0.55 , which indicates the presence of multimodality in the distribution of the considered variable.

Having confirmed the existence of multimodality, we would now like to ascertain the actual number of modes present in our estimated density functions. Silverman $(1981,1986)$ has emphasised the proper modelling of the number of modes and has presented a test for multimodality and

\footnotetext{
${ }^{13}$ In particular, the growth rates of the real GDP per capita over the decade from 1992 to 2001 were negative in 66 districts. Out of these 66, seven districts (Delmenhorst, Landkreis Holzminden, Landkreis Sigmaringen, Landkreis Soltau-Fallingborstel, Landkreis Unterallgäu, Neustadt an der Weinstrasse, Wilhelmshaven) have even experienced two-digit negative growth rates. Following Jones $(1998$, p. 4) these districts might be labeled "growth disasters".
} 
peakedness. ${ }^{14}$ The test may help interpreting the evolution of regional inequalities across German districts.

Table 1: Timm's (2002) Bimodality Index

\begin{tabular}{||c|c||}
\hline YEAR & TEST STATISTIC \\
\hline 1992 & 1.23 \\
\hline 1994 & 1.11 \\
\hline 1995 & 1.23 \\
\hline 1996 & 1.29 \\
\hline 1997 & 1.38 \\
\hline 1998 & 1.42 \\
\hline 1999 & 1.56 \\
\hline 2000 & 1.68 \\
\hline 2001 & 1.76 \\
\hline
\end{tabular}

The non-parametric procedure tests the null hypothesis that a density $f$ has $k$ modes (or peaks, bumps) against the alternative that $f$ has more than $k$ modes, where $k$ is a non-negative integer. The test statistic in this case is the critical window width, defined by

$$
h_{\text {crit }}(k)=\inf \{h \mid \hat{f} \text { has at most } k \text { modes }\} \text {. }
$$

For $h<h_{\text {crit }}(k)$, the estimated density has at least $k+1$ modes. The basic idea of the test is intuitive and simple. Specifically, if the series has $k$ modes, then $h_{\text {crit }}(k-1)$ should be 'large' because substantial smoothing is required to generate a $(k-1)$-mode density. For example, if the data possess two strong modes, a large value of $h$ will be needed to obtain an unimodal estimate. An illustrative calculation of the critical window widths $h$ and the corresponding number of modes (peaks) in the kernel density estimates for the year 1999 is plotted in Figure 3.

\footnotetext{
${ }^{14}$ This test of multimodality has been used by Bianchi (1997) to test the hypothesis of income convergence for a group of 119 countries between the years of 1970 and 1989. Bianchi (1997) rejects the hypothesis of convergence in favour of the formation of convergence clubs.
} 


\section{Figure 3: Number of Modes in the Kernel Density Estimate as a Function of the Window} Width Size $h, 1999$

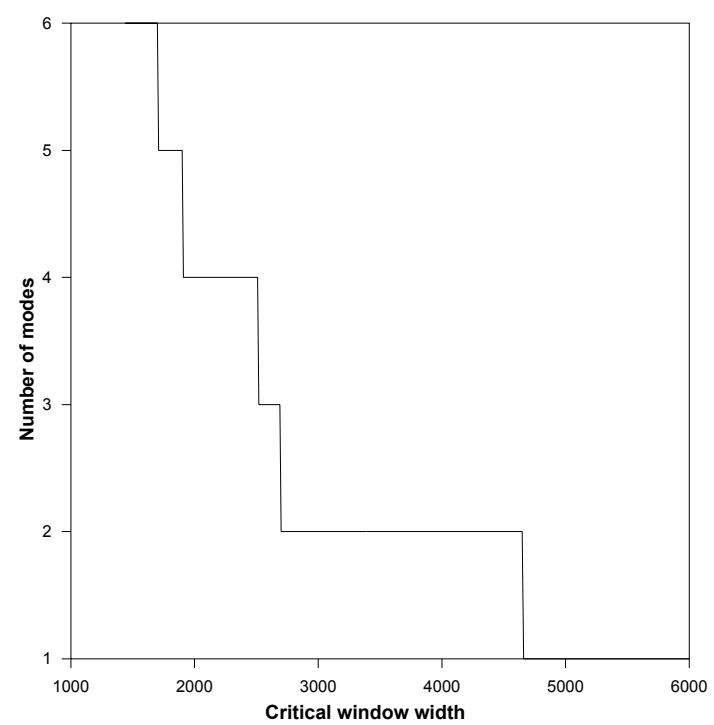

Thus, the technique forms a natural hypothesis-testing framework since large numbers of $h_{c r i t}(k)$ indicate more than $k$ modes. The crucial question, then, becomes how large is "large" when the chosen bandwidth is concerned. The value of $h_{\text {crit }}(k)$ is computed through a binary search algorithm, and its significance level can be assessed by the bootstrap procedure attributable to Efron (1979). In particular, the bootstrap test requires a statistic test $t(x)$ and an estimated null distribution for the data under $H_{0}$. Given these, the $p$-value of the test is

$$
p_{\text {bootstrap }}=\operatorname{prob}_{\hat{F}_{0}}\left\{t\left(x^{*}\right)>t(x)\right\}
$$

where

$$
x^{*}=\left(x_{1}^{*}, x_{2}^{*}, \ldots, x_{n}^{*}\right)^{\prime}
$$

is the bootstrap drawn from the null distribution $\hat{F}_{0}$. To approximate $p_{\text {bootstrap }}$, bootstrap samples have to be drawn from a rescaled density estimate obtained by setting

$$
x_{i}^{*}=\bar{y}^{*}+\sqrt{1+\frac{h^{2}}{\hat{\sigma}^{2}}}\left(y_{i}^{*}-\bar{y}^{*}+h \varepsilon\right),
$$

where $\sqrt{1+h^{2} / \hat{\sigma}^{2}}$ is the rescaling factor, $y_{i}^{*}$ are sampled with replacement from the original sample, $\bar{y}^{*}$ its mean, $\hat{\sigma}^{2}$ its variance and $\varepsilon$ is assumed to be distributed as a standard normal since 
the kernel is Gaussian. ${ }^{15}$ In other words, the bootstrap method treats the available sample as the population, and through repeated re-sampling of this sample, obtains the distribution of statistics of the test. A sample is taken of the original series (with replacement) and transformed to have the same first and second moments. Critical values are then obtained by generating a large number of samples. ${ }^{16}$ This is not a nested test and its results should therefore be interpreted as a hierarchical set of significance tests. ${ }^{17}$

We execute the Silverman $(1981,1986)$ test for each year, with null hypotheses of one, two and three modes (hence alternative hypotheses of more than one, more than two and more than three modes).

Table 2: Silverman's Multimodality Test

\begin{tabular}{|c|c|c|c|c|}
\hline YEAR & \multicolumn{3}{|c|}{ CRITICAL BANDWIDTHS AND $P$-VALUES } & $k^{*}$ \\
\hline & $h_{\text {crit }(I)}$ & $h_{\text {crit }(2)}$ & $h_{\text {crit }(3)}$ & \\
\hline 1992 & $\begin{array}{l}2490 \\
{[0.00]}\end{array}$ & $\begin{array}{l}2240 \\
{[0.00]}\end{array}$ & $\begin{array}{l}1780 \\
{[0.16]}\end{array}$ & 3 \\
\hline 1994 & $\begin{array}{l}2530 \\
{[0.00]}\end{array}$ & $\begin{array}{l}2170 \\
{[0.12]}\end{array}$ & $\begin{array}{l}1600 \\
{[0.21]}\end{array}$ & 2 \\
\hline 1995 & $\begin{array}{l}3120 \\
{[0.00]}\end{array}$ & $\begin{array}{l}2960 \\
{[0.08]}\end{array}$ & $\begin{array}{l}1590 \\
{[0.19]}\end{array}$ & 3 \\
\hline 1996 & $\begin{array}{l}3760 \\
{[0.00]}\end{array}$ & $\begin{array}{l}2640 \\
{[0.13]}\end{array}$ & $\begin{array}{l}1810 \\
{[0.26]}\end{array}$ & 2 \\
\hline 1997 & $\begin{array}{l}3060 \\
{[0.00]}\end{array}$ & $\begin{array}{l}3200 \\
{[0.06]}\end{array}$ & $\begin{array}{l}1930 \\
{[0.10]}\end{array}$ & 3 \\
\hline 1998 & $\begin{array}{l}3910 \\
{[0.07]}\end{array}$ & $\begin{array}{l}2570 \\
{[0.19]}\end{array}$ & $\begin{array}{l}1860 \\
{[0.35]}\end{array}$ & 2 \\
\hline 1999 & $\begin{array}{l}4660 \\
{[0.00]}\end{array}$ & $\begin{array}{l}2700 \\
{[0.10]}\end{array}$ & $\begin{array}{l}1860 \\
{[0.08]}\end{array}$ & 2 \\
\hline 2000 & $\begin{array}{l}3875 \\
{[0.00]}\end{array}$ & $\begin{array}{l}2530 \\
{[0.10]}\end{array}$ & $\begin{array}{l}1710 \\
{[0.14]}\end{array}$ & 2 \\
\hline 2001 & $\begin{array}{l}3620 \\
{[0.00]}\end{array}$ & $\begin{array}{l}3130 \\
{[0.05]}\end{array}$ & $\begin{array}{l}2710 \\
{[0.09]}\end{array}$ & 3 \\
\hline
\end{tabular}

Notes: Bootstrapped $p$-values in $[\cdot] \mathrm{s}$.

The results are listed in Table 2, with the first row for any given year indicating the values of $h_{c r i t}(k)$; the $p$-values associated with the corresponding critical value widths are given in parentheses; and $k^{*}$ representing the number of modes detected.

${ }^{15}$ Rescaling is necessary since the kernel estimation artificially increases the variance of the estimate [see Efron and Tibshirani (1993)]. Since the procedure samples from a smooth estimate of the population, it is called smooth bootstrap.

${ }^{16}$ In our simulations we set the number of bootstrap replications to 3000. It is well-known [see Izenman and Sommer (1988) and Hall and York (2001) for a detailed account] that the Silverman test tends to suffer from low power and accordingly probability values higher than conventional ones are typically used. One therefore has to be aware that inference on the state number retains some judgemental element. 
Taken together, the BM index establishes the presence of multimodality while the Silverman test suggests a persistent ambiguity between trimodality and bimodality over the time period, consistent with the "eye-ball evidence" drawn from Figures 1 and $2 .^{18}$

In order to geographically illustrate the clusters detected in the Kernel density estimations, we have produced a set of maps, Figures 4 and 5, which create a visual impression of the spatial structure of the real GDP per capita across German districts. The categories are defined such that in each income range there resides an equal number of districts. To be consistent with the results of our empirical analysis we have chosen to identify three and six categories of the real GDP per capita in 1992 and in 2001, the first and the last year of the considered time span. The presented maps provide evidence that spatial clusters do exist for the variable under consideration. ${ }^{19}$ In particular, as one would expect, the poorest district are concentrated in East Germany. In 1992, all districts, except Berlin, Kreisfreie Stadt Potsdam and Kreisfreie Stadt Erfurt, belong to the "poorest" group, ${ }^{20}$ whereas only 10 percent of the West districts are included in this low-income cluster. By 2001, the proportion of Eastern districts that still reside in this same cluster has shrunk to 80 percent of the total Eastern districts. However, a number of districts have switched to the richer groups, showing an improvement in their relative income level. In particular, the districts in the greater Berlin area have moved from the low- to the middle-income group. ${ }^{21}$ Furthermore, 8 percent of the Eastern German districts (Kreisfreie Stadt Dresden, Kreisfreie Stadt Rostock, Kreisfreie Stadt Cottbus, Kreisfreie Stadt Neubrandenburg, Kreisfreie Stadt Jena, Kreisfreie Stadt Erfurt, Kreisfreie Stadt Schwerin, Kreisfreie Stadt Zwickau, Kreisfreie Stadt Potsdam) have gained a foothold amongst the richest elite by 2001 .

\footnotetext{
${ }^{17}$ Although the Silverman $(1981,1986)$ test is flexible in its hypothesis, it does have the disadvantage of not being a nested test. For example, it could fail to reject the null hypothesis of having $k$ modes, but reject the null of having $k-p$ modes, where $k-p \geq 0$.

${ }^{18}$ We have also examined the distribution of each district's per capita income relative to Hamburg's income. This does not change the shape of the distribution, and the results are virtually identical.

${ }^{19}$ For the correct interpretation of the maps it is important to bear in mind that they are not suitable to assess the absolute growth performance of the 439 German districts: in particular, it is not possible to say whether over the last decade the poorest areas caught up with the richest ones or whether some areas got richer or poorer as they switched from a cluster to another. (The reason for that is that the thresholds defining the identified categories have changed over time). Looking at those thresholds - which all rose considerably - it is indeed possible to state that the average German GDP has risen between 1992 and 2001.

${ }^{20}$ Data for Mecklenburg-Vorpommern (18 Kreise) is not available for 1992. However, their per capita income level is found to reside within the lowest income category as soon as these figures become available in 1996.

${ }^{21}$ Landkreis Teltow-Fläming and Landkreis Dahme-Spreewald.
} 

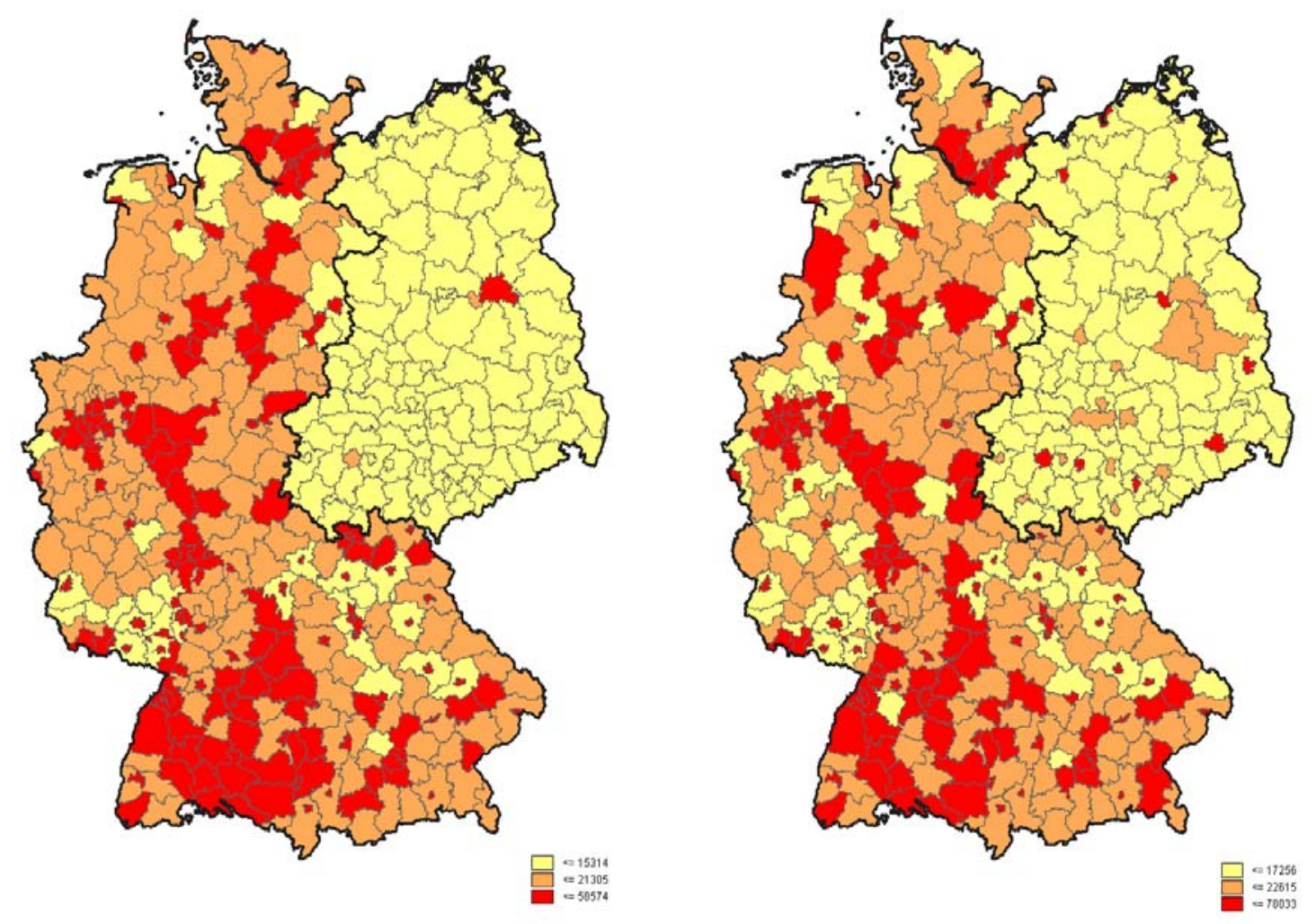

Notes: The thin lines indicate the regional boundaries of the 439 districts, the thick lines indicate the East German states and districts .

A further piece of information that can be gleaned from the visual inspection of the maps is that approximately 40 percent of West Germany belongs to the high-income cluster, both in 1992 and in 2001, with a high concentration of rich districts localized in the Hamburg area to the North, as well as in the western and southern parts of West Germany. One surprising feature that emerges is the marked downturn in the fortunes of 24 Western districts, who experienced a erosion of their per capita GDP from above 21,300 euros in 1992 to 17,200 euros in $2001 .^{22}$

All in all, the comparison between 1992 and 2001 shows that the spatial structure of the real GDP per capita of German districts over the last decade has indeed changed. Figure 4 shows that the relative income position of the East German districts has remained at the bottom of the ranking whereas districts located in the South-West and in the Hamburg area were still included in the 
richest group. In other words, the relatively "poorer" districts have remained clustered in the Eastern part of Germany and the "wealthier" areas have remained localized in the South-West. That said, the emergence of a number of wealthier Eastern districts concurrently with the fall-back experienced by a pocket of Western regions suggests that the overall picture may be more complex than first thought.

Figure 5 paints the same picture in greater detail as six different income groups are identified. This 6-category map allows a more precise view of the spatial structure of real GDP per capita across the German districts, while retaining a natural consistency with the 3-category map of Figure 4. Of the two lowest income ranges, the very poorest range is observed only in East Germany in 1992. By 2001, however, it is apparent from the more detailed 6-category maps that a number of West German states now reside in this lowest category, particularly in the north and south-west. Within the East there is also a discernible movement from the lowest income range to the second lowest, over the period in question. In the middle income ranges there has been a perceptible emergence of middle-income category districts in the East German states over the 1992-2001 time period, whereas in the West those regions residing in the middle income ranges in 1992 have broadly retained their status throughout the period. Similar to the trends observed in Figure 4, the relatively wealthier regions tend to be concentrated in the west and southern areas of the country in both 1992 and 2001. One can also discern the emergence of a sprinkling of relatively wealthy regions in the East by 2001, due perhaps to real GDP growth associated with urban, commercial areas such as Berlin and Dresden.

Taken as a whole, the visual impression created in Figures 4 and 5 of the spatial structure of the real GDP per capita leads one to conclude the following: over the period 1992-2001 there has been a noticeable catching-up process in terms of the real GDP of Eastern German regions; West German regions that have been residing in middle income ranges tend to have retained this status throughout the period in question, though as illustrated by the 6-category maps a small number of western regions which were in the lower income categories in 1992 have fallen back somewhat by 2001; the relatively richer clusters in the western and southern areas of the country have consolidated their position over the period in question, while a sprinkling of relatively wealthy regions has also emerged in the East.

\footnotetext{
${ }^{22}$ In 2001 the share of Western districts included in the low-income group over the total number of West German districts rose to 18 percent (58 out of a total of 326 West German districts) from 10 percent in 1992.
} 

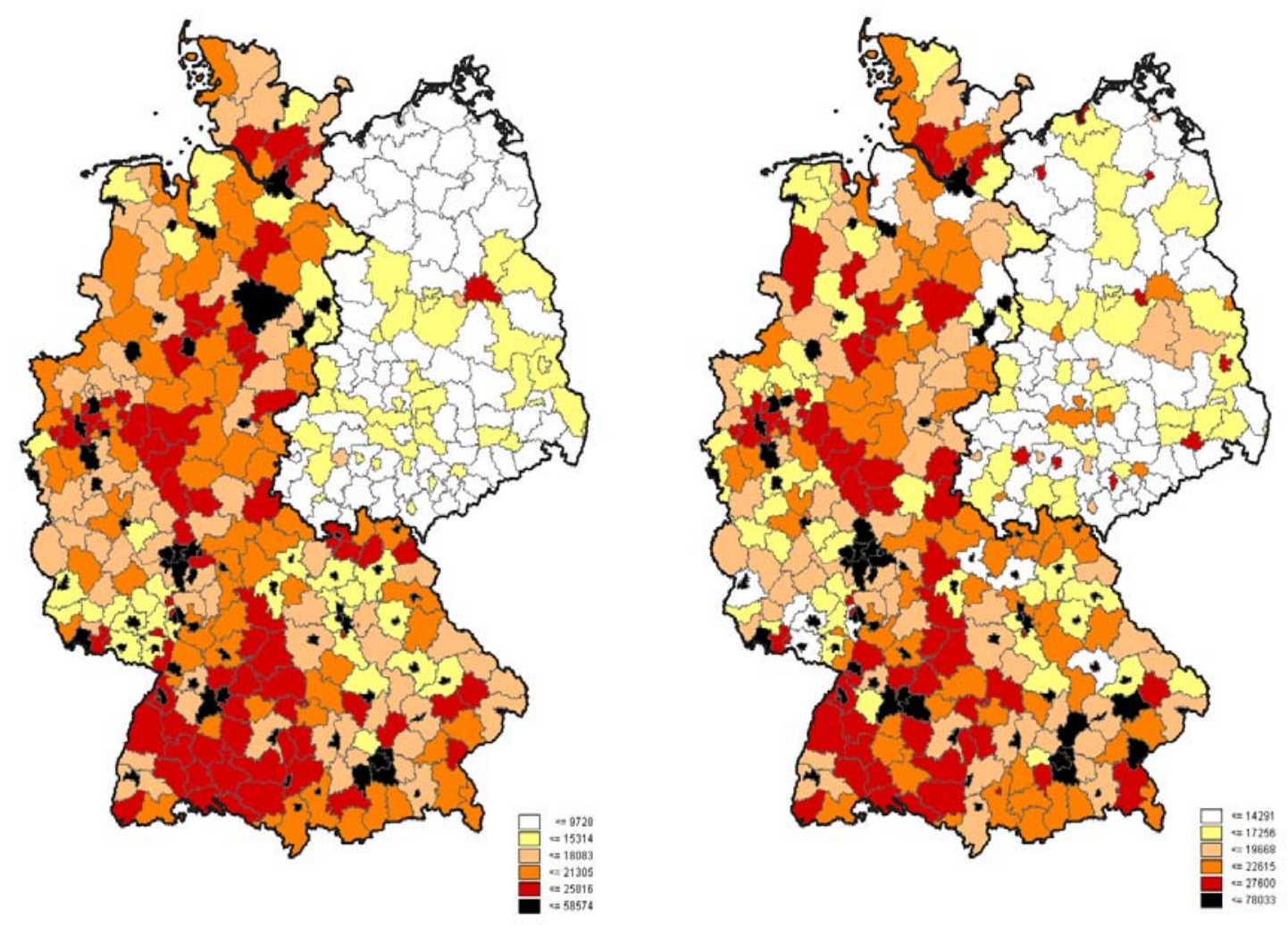

Notes: The thin lines indicate the regional boundaries of the 439 districts, the thick lines indicate the East German states and districts .

\section{A Nonparametric Test of Density Time Invariance}

The visual impression from the density estimates in Figures 1 and 2 is that the per capita income densities have indeed changed across time. In order to determine whether this "eye-ball evidence" is statistically significant, Li's (1996) nonparametric test has been carried out.

Let $f(x)$ and $g(x)$ denote two bounded and continuous probability density functions observed in two different time periods. The null hypothesis of the test is $\mathrm{H}_{0}: f(x)=g(x)$, against $\mathrm{H}_{1}: f(x) \neq g(x) .{ }^{23}$ Given the observations $X=\left(X_{1}, \ldots, X_{n}\right)$ and $Y=\left(Y_{1}, \ldots, Y_{n}\right)$ drawn from the unknown density

\footnotetext{
${ }^{23}$ For the sake of simplicity, we assume the samples of observations on $X$ and $Y$ to be of equal sizes. The extension of the test for the case of different sample sizes is easy. Furthermore, the random variables $X$ and $Y$ need not be independent in the sense that the possible dependence does not change the asymptotic distribution of the test statistic.
} 
functions $f_{X}$ and $f_{Y}$ the test is based on the integrated squared difference between $f_{X}$ and $f_{Y}$ denoted by $I$ and defined by:

$$
I=\int\left[f_{X}(t)-f_{Y}(t)\right]^{2} d t
$$

$$
I=\int\left[f_{X}^{2}(t)+f_{Y}^{2}(t)-2 f_{X}(t) f_{Y}(t)\right] d t
$$

$$
I=\int f_{X}(t) d F_{X}(t)+\int f_{Y}(t) d F_{Y}(t)-2 \int f_{Y}(t) d F_{X}(t)
$$

where $F_{X}$ and $F_{Y}$ are the distribution functions. In our application, $f_{X}$ and $f_{Y}$ correspond to the distributions from different years, i.e. $f_{X}$ and $f_{Y}$ are the per capita GDP distributions in period $t$ and $t+i$, respectively. The feasible estimator of $I$, denoted by $I_{n}$, can be obtained if one substitutes the density functions $f_{X}$ and $f_{Y}$ by their kernel estimates

$$
\hat{f}_{X}(x)=\frac{1}{n h} \sum_{i=1}^{n} K\left(\frac{X_{i}-x}{h}\right)
$$

and

$$
\hat{f}_{Y}(x)=\frac{1}{n h} \sum_{i=1}^{n} K\left(\frac{Y_{i}-x}{h}\right)
$$

Using these estimates and replacing $F_{X}$ and $F_{Y}$ by their empirical distribution functions, one can write $I_{n}=I_{1 n}+I_{2 n}$, where

$$
I_{1 n}=\frac{2 K(0)}{n h}-\frac{2}{n^{2} h} \sum_{i=1}^{n} K\left(\frac{X_{i}-Y_{i}}{h}\right)
$$

and

$$
I_{2 n}=\frac{1}{n^{2} h} \sum_{\substack{i=1 \\ j}}^{n} \sum_{j=j}^{n}\left[K\left(\frac{X_{i}-X_{j}}{h}\right)+K\left(\frac{Y_{i}-Y_{j}}{h}\right)-K\left(\frac{Y_{i}-X_{j}}{h}\right)-K\left(\frac{X_{i}-Y_{j}}{h}\right)\right]
$$

Under the null hypothesis of time invariance, Li (1996) has shown that the test statistic which is based on global closeness between two unknown density functions, is given by: 


$$
T_{n}=n h^{1 / 2}\left(\frac{I_{n}-\frac{2 K(0)}{n h}}{\hat{\sigma}}\right) \stackrel{d}{\longrightarrow} N(0,1)
$$

where:

$$
\hat{\sigma}=\frac{1}{n^{2} h} \sum_{i=1}^{n} \sum_{j=1}^{n}\left[K\left(\frac{X_{i}-X_{j}}{h}\right)+K\left(\frac{Y_{i}-Y_{j}}{h}\right)+2 K\left(\frac{X_{i}-Y_{j}}{h}\right)\right]\left[\int K^{2}(t) d t\right] .
$$

Li (1996) has shown that the test statistic has a convergence rate faster than the $\sqrt{n}$ rate. The Monte Carlo results indicate that the test performs well for sample size $n \geq 50$ when $n_{l}=n_{2}=n{ }^{24}$ The results of the pairwise comparison over time are reported in Table 3 and 4.

Table 3: The Li (1996) $T_{n}$ Test Statistics for $n=419$

\begin{tabular}{||c|c||}
\hline \hline TIME COMPARISON & TEST STATISTIC \\
\hline 1992 versus 1994 & $8.68^{* * *}$ \\
\hline 1994 versus 1996 & 0.12 \\
\hline 1996 versus 1998 & 0.47 \\
\hline 1998 versus 2000 & $1.40^{*}$ \\
\hline 1992 versus 2001 & $9.96^{* * *}$ \\
\hline
\end{tabular}

Note: $(* * *),(* *)$ and $(*)$ indicates significance at the $1 \%$, the $5 \%$ and the $10 \%$ level, respectively.

Table 4: The Li (1996) $T_{n}$ Test Statistics for $n=439$

\begin{tabular}{||c|c||}
\hline TIME COMPARISON & TEST STATISTIC \\
\hline 1996 versus 1998 & 0.49 \\
\hline 1998 versus 2000 & $1.38^{*}$ \\
\hline 1996 versus 2001 & $3.36^{* * *}$ \\
\hline
\end{tabular}

Note: $(* * *)$ and $(*)$ indicates significance at the $1 \%$ and the $10 \%$ level, respectively.

As shown in Table 3 and 4, there is one highly significant change in the distribution occurring within the first two years after unification.

Since the hypothesis of unimodal convergence is rejected by nonparametric methods, we finally use the methodology of distributional dynamics to model the evolution of the relative distribution of per capita incomes for Germany districts. This approach models directly the evolution of relative income distributions by constructing transition probability matrices that track changes over time in the relative position of districts within the distribution. This is an exercise that a number of authors have

\footnotetext{
${ }^{24}$ Alternatively, Li (1996) has also suggested a $J_{n}$ and $J_{n c}$ test statistic, respectively. The Monte Carlo evidence indicates that $J_{n c}$ has a significant negative bias, while $J_{n}$ and $T_{n}$ have similar power.
} 
undertaken (see Quah, 1996, 1997). The modelling of distribution dynamics assumes that the density distribution $\phi_{t}$ has evolved in accordance with the following equation:

$$
\phi_{t+1}=M \phi_{t}
$$

where $M$ is an operator that maps the transition between the income distributions for the periods $t$ and $t+1$. Since the density distribution $\phi$ for the period $t$ only depends on the density $\phi$ for the immediately previous period, this is a first-order Markov process. In our estimates below we have assumed that the distribution $\phi$ has a finite number of states. For the Markov transition matrices we assume that the probability of variable $s_{t}$ taking on a particular value $j$ depends only on its past value $s_{t-1}$ according to the first-order Markov chain

$$
P\left\{s_{t}=\left.j\right|_{s_{t-1}}=i\right\}=P_{i j},
$$

where $P_{i j}$ indicates the probability that state $i$ will be followed by state $j$. As

$$
P_{i 1}+P_{i 2}+\ldots+P_{i n}=1
$$

we may construct the so-called transition matrix

$$
P=\left[\begin{array}{cccc}
P_{11} & P_{12} & \ldots & P_{1 n} \\
P_{21} & P_{22} & \ldots & P_{2 n} \\
\ldots & \ldots & \ldots & \ldots \\
P_{n 1} & P_{n 1} & \ldots & P_{n n}
\end{array}\right]
$$

where line $i$ and column $j$ give the probability that state $i$ will be followed by state $j$. In our modelling approach, the probability $P_{i j}$ measures the proportion of districts in regime $i$ during the previous period that migrate to regime $j$ in the current period. According to Geweke et al. (1986), the maximum likelihood estimator for the transition probability $\hat{P}_{i j}$ is given by:

$$
\hat{P}_{i j}=\frac{\sum n_{i j}}{\sum n_{i}}
$$

where $\sum n_{i j}$ is the number of districts that were in income category $i$ in the previous period and have migrated to income category $j$ in the current period, and $\sum n_{i}$ is the total of districts that were is 
income category $i$ in the previous period. The main advantage of the transition matrix is that it allows to summarise the random ups and down of regional fortunes in a handful of numbers.

The transition probability matrix in Table 5 reports transitions between the 1992 and 2001 distributions of GDP per capita relative to the German average. ${ }^{25}$ The main diagonal of the matrix gives the proportion of districts that were in the same range of the distribution immediately after German unification as a decade later. Table 5 also provides information about $n$, the number of districts that begin their transitions in a given state. Furthermore, we provide the classes that divide up the state space.

Table 5: Transition Probability Matrix Relative to the German Average

\begin{tabular}{|c|c|c|c|c|c|c|c|c|}
\hline & \multicolumn{8}{|c|}{ "GDP PER CAPITA 2001} \\
\hline \multirow{8}{*}{$\begin{array}{l}\text { GDP } \\
\text { PER } \\
\text { CAPITA } \\
1992\end{array}$} & $n$ & & 4 & 61 & 79 & 128 & 74 & 73 \\
\hline & 63 & {$[0-0.5]$} & 0.03 & 0.68 & 0.27 & 0.02 & 0.00 & 0.00 \\
\hline & 30 & {$[0.5-0.65]$} & 0.07 & 0.40 & 0.33 & 0.17 & 0.03 & 0.00 \\
\hline & 45 & {$[0.65-0.8]$} & 0.00 & 0.13 & 0.53 & 0.22 & 0.11 & 0.00 \\
\hline & 106 & \begin{tabular}{|l}
{$[0.8-1.00]$} \\
\end{tabular} & 0.00 & 0.00 & 0.26 & 0.70 & 0.04 & 0.00 \\
\hline & 90 & {$[1.00-1.25]$} & 0.00 & 0.00 & 0.00 & 0.41 & 0.57 & 0.02 \\
\hline & 85 & {$[1.25-\infty]$} & 0.00 & 0.00 & 0.00 & 0.01 & 0.15 & 0.83 \\
\hline & & & {$[0-0.5]$} & {$[0.5-0.65]$} & {$[0.65-0.8]$} & {$[0.8-1.0]$} & {$[1.0-1.25]$} & {$[1.25-\infty]$} \\
\hline
\end{tabular}

The salient characteristics of the transition probability matrix in Table 5 reveal a number of noteworthy behavioural patterns in the distribution of real GDP over time. First, as indicated by the first element of the main diagonal (0.03), districts which originally reside in the lowest range of the distribution (i.e. with a GDP per capital of $50 \%$ or less of the German average) appear to be very unlikely to remain in this category at the end of the period in question. Such districts display a strong tendency to either move forward to the second category (0.68) or jump to the third category $(0.27)$. Second, the third and fourth elements of the main diagonal (a real GDP of $65 \%-80 \%$ and $80 \%-100 \%$ of the German average, respectively) indicate a relatively high probability for the regions within this range to maintain their status quo over the period. That said, regions in the third category appear to be relatively open to backward or forward movements (with probabilities of 0.13 and 0.22 respectively) while those in the fourth seem decidedly more backward looking, as illustrated by the 0.26 probability of moving a step back but only a mere 0.04 probability of moving forward one step. Finally, the districts residing in the fifth category (with a real GDP of $100-125 \%$ of the average)

25 Only districts that were part of the dataset at the beginning of the sample period are included in the calculation. 
appear to be more likely to either retain this position or fall back by one category. These districts marked inability to move forward (a probability of 0.02 ) suggests there comes a point where incremental increases in real GDP become harder and harder to sustain. Furthermore, those districts that reside in the highest income category at the beginning of the time period display a very high probability $(0.83)$ of consolidating their position of affluence.

The forementioned characteristics support the findings of kernel density estimation, namely: the tendency of the poorest districts to catch-up; the middle income districts retaining their status quo (despite a small number of their ranks back-peddling); and the consolidation of the richest districts of their position.

\section{Conclusions and further comments}

The objective of this paper is to address the question of convergence across German districts in the first decade after German unification by drawing out and emphasising some stylised facts of regional per capita income dynamics, rather than estimating any particular economic model. We achieve this by employing techniques which focus on the evolution of the entire cross-sectional income distribution. In particular, we follow a distributional approach to convergence based on nonparametric kernel density estimation and implement a number of tests to establish the statistical significance of our findings. The visual inspection of the estimated densities indicates the following: the presence of trimodality in 1992; in subsequent years less pronounced trimodality, supporting the notion of a catching-up process of eastern Germany in the early 1990s; and a tendency for the remaining two peaks to move apart, resulting in a swelling of the middle income mode and a more pronounced high income mode. This ambiguity between trimodality and bimodality over the period in question is supported by statistical tests such as the Silverman multimodality test and the BM index. It should be noted, of course, that empirical evidence suggesting bimodality runs counter to recent theoretical views. ${ }^{26}$

The colour-coded maps of the German districts geographically illustrate the clusters detected in the Kernel density estimations and provide evidence that spatial clusters of income do exist over the

\footnotetext{
${ }^{26}$ The exact nature of multimodality is indeed surrounded by some degree of uncertainty. At first glance, it might seem promising to consider growth model with multiple equilibria in the tradition of Aghion and Howitt (1998, Chapter 10), Azariadis (1996), Drazen and Azariades (1990) and Matsuyama (1991) when trying to explain "job-poor" versus "job-rich" growth experiences. In such models, a country may be trapped in a "jobpoor" equilibrium when, in principle at least, an alternative and superior equilibrium is also feasible. However, the recent literature has cast doubts on the robustness of multiple equilibria. Frankel and Pauzner (2000) analyse a two sector model with increasing returns, based upon Matsuyama (1991). They show that if the wage is stochastic and arrives as a Poisson process, the muliplicity property may be eliminated because some of the deterministic equilibria are more robust to perturbations than others. A similar conclusion has been established by Herrendorf et al. (1999) for heterogenous agents. They show that sufficient heterogeneity of agents will lead to a refinement in the set of observable equilibria and uniqueness in models like that of Matsuyama (1991).
} 
period in question. Consistent with the density estimates there emerges a picture of East German convergence, a swelling middle-income group and a more pronounced high-income group.

Li's (1996) nonparametric test lends statistical support to the forementioned visual impressions. Further additional information is captured by the transition probability matrix, which tracks changes over time in the relative position of districts within the distribution. The conclusions drawn from this exercise are once again consistent with those yielded by the analysis thus far.

An alternative approach to investigating the presence of convergence clubs would be to track in more detail the performance of each geographical unit. This may provide another dimension of disparity that is relevant for economic policy making. From a policy perspective, besides having information about the entire cross-section of observations, it is also important to know how likely is each district to improve its conditions, how many did so and what are their characteristics. In other words, whether or not districts that were rich (poor) a decade ago are the same ones that are rich (poor) now has relevant policy implications. If the poor regions are persistently poor, one may want to consider public programs aimed at enhancing the performance of these districts. On the other hand, if the incomes per capita are rotating over time, one would be less concerned about overall geographical income distribution. Our approach has not conceptualised this alternative mixing or ranking change aspect of disparity. Further consideration should be given to such indicators in future research. 


\section{References:}

Aghion, P. and P. Howitt (1998) Endogenous Growth Theory, Cambridge (MIT Press).

Azariadis, C. (1996) "The Economics of Poverty Traps Part One: Complete Markets", Journal of Economic Growth 1, 449-486.

Azariadis, C. and A. Drazen (1990) "Threshold Externalities in Economic Development", Quarterly Journal of Economics 105, 501-526.

Barro, R.J. (1991) "Economic Growth in a Cross-Section of Countries", Quarterly Journal of Economics 106, 407-443.

Bode, E. (2002) "Räumliches Muster des Aufholprozesses", in: IWH (ed.) Fortschrittsbericht wirtschaftswissenschaftlicher Institute über die wirtschaftliche Entwicklung in Ostdeutschland, Halle, 31-90.

Bianchi, M. (1997) "Testing for Convergence: Evidence from Non-Parametric Multimodality Tests", Journal of Applied Econometrics 12, 393-409.

Corrado, L., Martin, R. and M. Weeks (2005) "Identifying and Interpreting Regional convergence Clusters Across Europe", The Economic Journal 115, C133-C160.

Efron, B. (1979) "Bootstrap Methods - Another Look at the Jack-Knife", Annals of Statistics 7, 126.

Efron, B. and R.J. Tibshirani (1993) An Introduction to the Bootstrap, London (Chapman and Hall).

Faini, R. (1984) “Increasing Returns, Non-Traded Inputs, and Regional Development”, Economic Journal 94, 308-323.

Funke, M. and Niebuhr, A. (2005) "Threshold Effects and Regional Economic Growth - Evidence from West Germany", Economic Modelling 22, 61-80.

Geweke, J., Marshall, R.C. and G. Zarkin (1986) "Mobility Indices in Continuous Time Markov Chains", Econometrica 54, 1407-1423.

Hall, P. and M. York (2001) "On the Calibration of Silverman's Test for Multimodality", Statistica Sinica 11, 515-536.

Herrendorf, B., Valentinyi, A. and R. Waldmann (2000) "Ruling Out Multiplicity and Indeterminancy: The Role of Heterogeneity", Review of Economic Studies 67, 295-307.

Islam, N. (1998) "Growth Empirics: A Panel Data Approach - A Reply", Quarterly Journal of Economics 113, 325-329.

Izenman, A.J. and C.J. Sommer (1988) "Philatelic Mixtures and Multi-Modal Densities", Journal of the American Statistical Association 83, 941-953.

Jones, C.I. (1998) Introduction to Economic Growth, London (W.W. Norton \& Company).

Lee, K., Pesaran, M.H. and R. Smith (1997) "Growth and Convergence in a Multi-Country Empirical Stochastic Growth Model", Journal of Applied Econometrics 12, 357-392. 
Lee, K., Pesaran, M.H. and R. Smith (1998) "Growth Empirics: A Panel Data Approach - A Comment", Quarterly Journal of Economics 113, 319-323.

Li, Q. (1996) "Nonparametric Testing of Closeness Between Two Unknown Distribution Functions", Econometric Reviews 15, 261-274.

Lopez-Bazo, E. Vaya, E. and M. Artis (2004) "Regional Externalities and Growth: Evidence from European Regions”, Journal of Regional Science 44, 43-73.

Magrini, S. (2004) "Regional (Di)Convergence", in: Henderson, J.V. and J.-F. Thisse (eds.) Handbook of Regional and Urban Economics, Vol. 4, Amsterdam (Elsevier), 2741-2796.

Mankiw, N.G., Romer, D. and D.N. Weil (1992) "A Contribution to the Empirics of Economic Growth", Quarterly Journal of Economics 107, 407-437.

Matsuyama, K. (1991) "Increasing Returns, Industrialization and Indeterminancy of Equilibrium", Quarterly Journal of Economics 106, 617-650.

Murphy, K.M., Shleifer, A. and R.W. Vishny (1989) "Industrialization and the Big Push", Journal of Political Economy 97, 1003-1293.

Nelson, R. (1956) "A Theory of the Low-Level Equilibrium Trap in Underdeveloped Economies", American Economic Review 46, 394-408.

Paap, R. and H.K. van Dijk (1998) "Distribution and Mobility of Wealth of Nations", European Economic Review 42, 1269-1293.

Park, B.U. and B.A. Turlach (1992) "Practical Performance of Several Data Driven Bandwidth Selectors (with Discussion)", Computational Statistics 7, 251-285.

Pittau, M.G. (2005) "Fitting Regional Income Distributions in the European Union", Oxford Bulletin of Economics and Statistics 67, 135-161.

Quah, D.T. (1996) "Convergence Empirics Across Economies with (some) Capital Mobility", Journal of Economic Growth 1, 95-124.

Quah, D.T. (1997) "Empirics for Growth and Distribution: Stratification, Polarization, and Convergence Clubs", Journal of Economic Growth 2, 27-59.

Rodrik, D. (1996) "Coordination Failure and Government Policy: A Model with Applications to East Asia and Eastern Europe", Journal of International Economics 40, 1-22.

Silverman, B.W. (1981) "Using Kernel Density Estimates to Investigate Multimodality", Journal of the Royal Statistical Society 43, 97-99.

Silverman, B.W. (1986) Density Estimation for Statistics and Data Analysis, London (Chapman and Hall).

Sims, C.A. and H. Uhlig (1991) "Understanding Unit Rooters: A Helicopter Tour", Econometrica 59, 1591-1600.

Sinn, H.W. and Sinn G. (1992). Jumpstart. The Economic Unification of Germany, MIT Press, Cambridge, Mass.

Solow, R.M. (1956) "A Contribution to the Theory of Economic Growth", Quarterly Journal of Economics 70, 65-94. 
Timm, N.H. (2002) Applied Multivariate Analysis, Berlin (Springer Verlag).

Wand, M.P. and M.C. Jones (1995) Kernel Smoothing, London (Chapman and Hall). 


\section{CESifo Working Paper Series}

(for full list see www.cesifo-group.de)

1469 Torberg Falch and Marte Rønning, The Influence of Student Achievement on Teacher Turnover, May 2005

1470 John Komlos and Peter Salamon, The Poverty of Growth with Interdependent Utility Functions, May 2005

1471 Hui Huang, Yi Wang, Yiming Wang, John Whalley and Shunming Zhang, A Trade Model with an Optimal Exchange Rate Motivated by Current Discussion of a Chinese Renminbi Float, May 2005

1472 Helge Holden, Lars Holden and Steinar Holden, Contract Adjustment under Uncertainty, May 2005

1473 Kai A. Konrad, Silent Interests and All-Pay Auctions, May 2005

1474 Ingo Vogelsang, Electricity Transmission Pricing and Performance-Based Regulation, May 2005

1475 Spiros Bougheas and Raymond Riezman, Trade and the Distribution of Human Capital, June 2005

1476 Vesa Kanniainen, Seppo Kari and Jouko Ylä-Liedenpohja, The Start-Up and Growth Stages in Enterprise Formation: The "New View" of Dividend Taxation Reconsidered, June 2005

1477 M. Hashem Pesaran, L. Vanessa Smith and Ron P. Smith, What if the UK had Joined the Euro in 1999? An Empirical Evaluation Using a Global VAR, June 2005

1478 Chang Woon Nam and Doina Maria Radulescu, Effects of Corporate Tax Reforms on SMEs' Investment Decisions under the Particular Consideration of Inflation, June 2005

1479 Panos Hatzipanayotou, Sajal Lahiri and Michael S. Michael, Globalization, CrossBorder Pollution and Welfare, June 2005

1480 John Whalley, Pitfalls in the Use of Ad valorem Equivalent Representations of the Trade Impacts of Domestic Policies, June 2005

1481 Edward B. Barbier and Michael Rauscher, Trade and Development in a Labor Surplus Economy, June 2005

1482 Harrie A. A. Verbon and Cees A. Withagen, Tradable Emission Permits in a Federal System, June 2005

1483 Hendrik Hakenes and Andreas Irmen, On the Long-Run Evolution of Technological Knowledge, June 2005 
1484 Nicolas Schmitt and Antoine Soubeyran, A Simple Model of Brain Circulation, June 2005

1485 Carsten Hefeker, Uncertainty, Wage Setting and Decision Making in a Monetary Union, June 2005

1486 Ondřej Schneider and Jan Zápal, Fiscal Policy in New EU Member States - Go East, Prudent Man!, June 2005

1487 Christian Schultz, Virtual Capacity and Competition, June 2005

1488 Yvan Lengwiler and Elmar Wolfstetter, Bid Rigging - An Analysis of Corruption in Auctions, June 2005

1489 Johannes Becker and Clemens Fuest, Does Germany Collect Revenue from Taxing Capital Income?, June 2005

1490 Axel Dreher and Panu Poutvaara, Student Flows and Migration: An Empirical Analysis, June 2005

1491 Bernd Huber and Marco Runkel, Interregional Redistribution and Budget Institutions under Asymmetric Information, June 2005

1492 Guido Tabellini, Culture and Institutions: Economic Development in the Regions of Europe, July 2005

1493 Kurt R. Brekke and Michael Kuhn, Direct to Consumer Advertising in Pharmaceutical Markets, July 2005

1494 Martín Gonzalez-Eiras and Dirk Niepelt, Sustaining Social Security, July 2005

1495 Alfons J. Weichenrieder, (Why) Do we need Corporate Taxation?, July 2005

1496 Paolo M. Panteghini, S-Based Taxation under Default Risk, July 2005

1497 Panos Hatzipanayotou and Michael S. Michael, Migration, Tied Foreign Aid and the Welfare State, July 2005

1498 Agata Antkiewicz and John Whalley, BRICSAM and the Non-WTO, July 2005

1499 Petr Hedbávný, Ondřej Schneider and Jan Zápal, A Fiscal Rule that has Teeth: A Suggestion for a 'Fiscal Sustainability Council' underpinned by the Financial Markets, July 2005

1500 J. Atsu Amegashie and Marco Runkel, Sabotaging Potential Rivals, July 2005

1501 Heikki Oksanen, Actuarial Neutrality across Generations Applied to Public Pensions under Population Ageing: Effects on Government Finances and National Saving, July 2005 
1502 Xenia Matschke, Costly Revenue-Raising and the Case for Favoring Import-Competing Industries, July 2005

1503 Horst Raff and Nicolas Schmitt, Why Parallel Trade may Raise Producers Profits, July 2005

1504 Alberto Bisin and Piero Gottardi, Efficient Competitive Equilibria with Adverse Selection, July 2005

1505 Peter A. Zadrozny, Necessary and Sufficient Restrictions for Existence of a Unique Fourth Moment of a Univariate GARCH(p,q) Process, July 2005

1506 Rainer Niemann and Corinna Treisch, Group Taxation, Asymmetric Taxation and Cross-Border Investment Incentives in Austria, July 2005

1507 Thomas Christiaans, Thomas Eichner and Ruediger Pethig, Optimal Pest Control in Agriculture, July 2005

1508 Biswa N. Bhattacharyay and Prabir De, Promotion of Trade and Investments between China and India: The Case of Southwest China and East and Northeast India, July 2005

1509 Jean Hindriks and Ben Lockwood, Decentralization and Electoral Accountability: Incentives, Separation, and Voter Welfare, July 2005

1510 Michelle R. Garfinkel, Stergios Skaperdas and Constantinos Syropoulos, Globalization and Domestic Conflict, July 2005

1511 Jesús Crespo-Cuaresma, Balázs Égert and Ronald MacDonald, Non-Linear Exchange Rate Dynamics in Target Zones: A Bumpy Road towards a Honeymoon - Some Evidence from the ERM, ERM2 and Selected New EU Member States, July 2005

1512 David S. Evans and Michael Salinger, Curing Sinus Headaches and Tying Law: An Empirical Analysis of Bundling Decongestants and Pain Relievers, August 2005

1513 Christian Keuschnigg and Martin D. Dietz, A Growth Oriented Dual Income Tax, July 2005

1514 Fahad Khalil, David Martimort and Bruno Parigi, Monitoring a Common Agent: Implications for Financial Contracting, August 2005

1515 Volker Grossmann and Panu Poutvaara, Pareto-Improving Bequest Taxation, August 2005

1516 Lars P. Feld and Emmanuelle Reulier, Strategic Tax Competition in Switzerland: Evidence from a Panel of the Swiss Cantons, August 2005

1517 Kira Boerner and Silke Uebelmesser, Migration and the Welfare State: The Economic Power of the Non-Voter?, August 2005 
1518 Gabriela Schütz, Heinrich W. Ursprung and Ludger Wößmann, Education Policy and Equality of Opportunity, August 2005

1519 David S. Evans and Michael A. Salinger, Curing Sinus Headaches and Tying Law: An Empirical Analysis of Bundling Decongestants and Pain Relievers, August 2005

1520 Michel Beine, Paul De Grauwe and Marianna Grimaldi, The Impact of FX Central Bank Intervention in a Noise Trading Framework, August 2005

1521 Volker Meier and Matthias Wrede, Pension, Fertility, and Education, August 2005

1522 Saku Aura and Thomas Davidoff, Optimal Commodity Taxation when Land and Structures must be Taxed at the Same Rate, August 2005

1523 Andreas Haufler and Søren Bo Nielsen, Merger Policy to Promote 'Global Players'? A Simple Model, August 2005

1524 Frederick van der Ploeg, The Making of Cultural Policy: A European Perspective, August 2005

1525 Alexander Kemnitz, Can Immigrant Employment Alleviate the Demographic Burden? The Role of Union Centralization, August 2005

1526 Baoline Chen and Peter A. Zadrozny, Estimated U.S. Manufacturing Production Capital and Technology Based on an Estimated Dynamic Economic Model, August 2005

1527 Marcel Gérard, Multijurisdictional Firms and Governments' Strategies under Alternative Tax Designs, August 2005

1528 Joerg Breitscheidel and Hans Gersbach, Self-Financing Environmental Mechanisms, August 2005

1529 Giorgio Fazio, Ronald MacDonald and Jacques Mélitz, Trade Costs, Trade Balances and Current Accounts: An Application of Gravity to Multilateral Trade, August 2005

1530 Thomas Christiaans, Thomas Eichner and Ruediger Pethig, A Micro-Level 'Consumer Approach' to Species Population Dynamics, August 2005

1531 Samuel Hanson, M. Hashem Pesaran and Til Schuermann, Firm Heterogeneity and Credit Risk Diversification, August 2005

1532 Mark Mink and Jakob de Haan, Has the Stability and Growth Pact Impeded Political Budget Cycles in the European Union?, September 2005

1533 Roberta Colavecchio, Declan Curran and Michael Funke, Drifting Together or Falling Apart? The Empirics of Regional Economic Growth in Post-Unification Germany, September 2005 